\title{
Cultivation OF OSCILlatoria SP IN DAIRY Waste Water In Two Stage PHoto Bioreactors For Biodiesel Production
}

\author{
Jitha. $\mathrm{G}^{1}$ and Madhu $\mathrm{G}^{2}$ \\ 1Research associate 2 Professor \\ Division of Safety and fire Engineering, School Of Engineering \\ Cochin University Of Science And Technology \\ Kochi-682022
}

\begin{abstract}
This paper presents an integrated approach to cultivate microalgae in dairy wastewater and to investigate the capability of the organism for biodiesel production. The present study was carried out using tolerant strains of microalgae collected from dairy effluent treatment plant, Kochi. Selected blue green algal strains were mass cultured in the laboratory and acclimatized using different concentrations of synthetic effluent. Blue green algal filaments were immobilized inside the primary and secondary photobioreactors. The experiment was conducted in two stages including batch and continuous treatment. The stage 1 of the experiment was designed for the reduction of physical impurities and the nutrients. Stage 2 was designed mainly for the cultivation of blue green algae in dairy waste water by utilizing the extra nutrients. Reduction of $94-99.5 \%$ in phosphate was observed after $48 \mathrm{~h}$ of treatment in the primary and secondary photobioreactors. The level of phosphate, total hardness, ammoniacal nitrogen in the MSE was reduced by $97 \%, 93 \%, 81 \%$ respectively. BOD was reduced to $370 \mathrm{mg} L^{-1}$ from $1500 \mathrm{mg} \mathrm{L}^{-1}$ after $48 \mathrm{hrs}$ of treatment in the primary reactor. COD was reduced to $85 \mathrm{mg} \mathrm{L}^{-1}$ from an initial value of $1500 \mathrm{mg} \mathrm{L}^{-1}$ from medium strength effluent (MSE) and 90-95\% removal of COD was also obtained from high strength effluent(HSE) during the study period. Biomass developed within the reactor was harvested at every 15 days intervals from the secondary reactor and analyzed for lipids and fattyacids. Presence of C14:0, C16:0,C18:0, C18:1 and C18:2 fatty acids strongly supports its abilility for biodiesel production.
\end{abstract}

\section{KEY WORDS}

Photobioreactor, Dairy effluent treatment, Blue green algae, Biomass production

\section{Introduction}

Dairy wastewaters can be remediated through assimilation of nutrients into algal biomass, which can be used as a resource material for various kinds of valuable products including pigments , biohydrogen, biofuels etc. There are a large number of studies on the treatment of industrial, municipal and agricultural waste waters by micro algal culture systems [1], [2]. Currently, there is a great deal of research looking to integrate microalgae cultivation and wastewater treatment (including municipal sewage, brewery wastewater, and dairy industry wastewater, etc.[3],[4], [5]. Cultivation of microalgae in dairy wastewater has received increased attention. The dairy effluent is predominantly organic in nature due to its biodegradable constituents. It is characterized by high $\mathrm{BOD}$, high $\mathrm{COD}$, and nutrients like $\mathrm{N}$ and $\mathrm{P}$ required for biological growth. Micro algae can grow well in these effluents because of its high nutrition content. Significant reduction in Total nitrogen, Total phosphorus and COD was obtained in Dairy waste 
water in both indoor and outdoor conditions [6]. Biological processes, such as activated sludge systems, involve an oxygen supply with an energy demand and extra sludge generation. While cultivation of microalgae in photobioreactor is advantageous in that it requires only sunlight, nutrients and $\mathrm{CO}_{2}$ for growth. Filamentous cyanobacteria form flocs which can be easily harvested from the reactor.Harvested biomass can be used for producing various products including biofuels. Microalgae based biodiesel is one of the promising alternatives to fossil fuels [7]. microalgae Nannochloropsis salina were cultivated in evaluated in anaerobically digested waste waters for biofuel production [8]. Present study was conducted to cultivate microalgae in photobioreactors and to evaluate the removal efficiency of phosphates, ammonia cal nitrogen, hardness in batch and continuous operation modes. Removal of organic pollution load was monitored as reduction in BOD and COD of effluent. The suitability of the harvested biomass for biofuel production was assessed by measuring type and relative proportions of fatty acids by GC analysis.

\section{Materials And Methods}

\subsection{Organism and Growth Condition}

Microalgal flocs were collected from the aeration tank of Effluent Treatment Plant (ETP), Milma Dairy, Kochi , Kerala were brought to the laboratory and inoculated in to BG 11 growth medium [9] and incubated under illumination from cool white fluorescent tubes at an intensity of 2000 lux and a temperature $30 \pm 3^{0} \mathrm{C}$ by using light/dark cycle of $12 \mathrm{~h}$. The blue green algal strains were identified using monograph of Desikachari [10]. Mass cultures of the of the organism were developed in 1L Erlenmeyer flasks using the BG 11 medium.

\subsection{Cultivation of Oscillatoria Sp. in Dairy Waste Water}

Synthetic dairy waste water was prepared as per the data collected from the Milma dairy, Kochi by adding $\mathrm{K}_{2} \mathrm{HPO}_{4}, \mathrm{NH}_{4} \mathrm{Cl}, \mathrm{MgSO}_{4}, \mathrm{Na}_{2} \mathrm{CO}_{3}$, glucose, Milk powder, yeast extract and starch. The cultures were gradually acclimatized to different effluent concentration in the medium $(0.2 \%(\mathrm{v} / \mathrm{v}), 0.4 \%(\mathrm{v} / \mathrm{v}), 0.6 \%(\mathrm{v} / \mathrm{v}), 0.8 \%(\mathrm{v} / \mathrm{v})$. Acclimatized strains were mass cultured and used for further study.

\subsection{Biomass Concentration and Specific Growth Rate}

The biomass produced in both BGII and synthetic waste water was filtered, and the dry weight was estimated at intervals of 2 days. The process was repeated up to 12 days. Specific growth rate during the culture period was obtained by equations below:

Specific growth rate $\left(\right.$ day_1 $\left._{-}\right)=\operatorname{Ln}\left(\mathrm{X}_{\mathrm{t}} / \mathrm{X}_{0}\right) /\left(\mathrm{t}_{-} \mathrm{t}_{0}\right)$, where $\mathrm{X}_{\mathrm{t}}$ and $\mathrm{X}_{0}$ are biomass density at time $\mathrm{t}$ and $t_{0}$ (at the beginn

\subsection{Experimental Set Up and Working}

Laboratory scale rectangular photo bioreactors having working volume $10 \mathrm{~L}$ and $30 \mathrm{~L}$ were fabricated using perspex glass sheet of thickness $6 \mathrm{~mm}$. A two stage model was set up for the treatment of the dairy waste water and biomass production. Inlet and outlet of both the reactors were fitted with PVC pipe having valve to control the flow rates. Primary reactor was layered with burned coconut shells at the bottom ( 2 inches) and woven coconut threads above( 2 inches) as filter bed. The inner space of the secondary reactor was divided into 5 compartments by providing baffles at regular intervals allowing zig zag flow of waste water( Fig 1). 


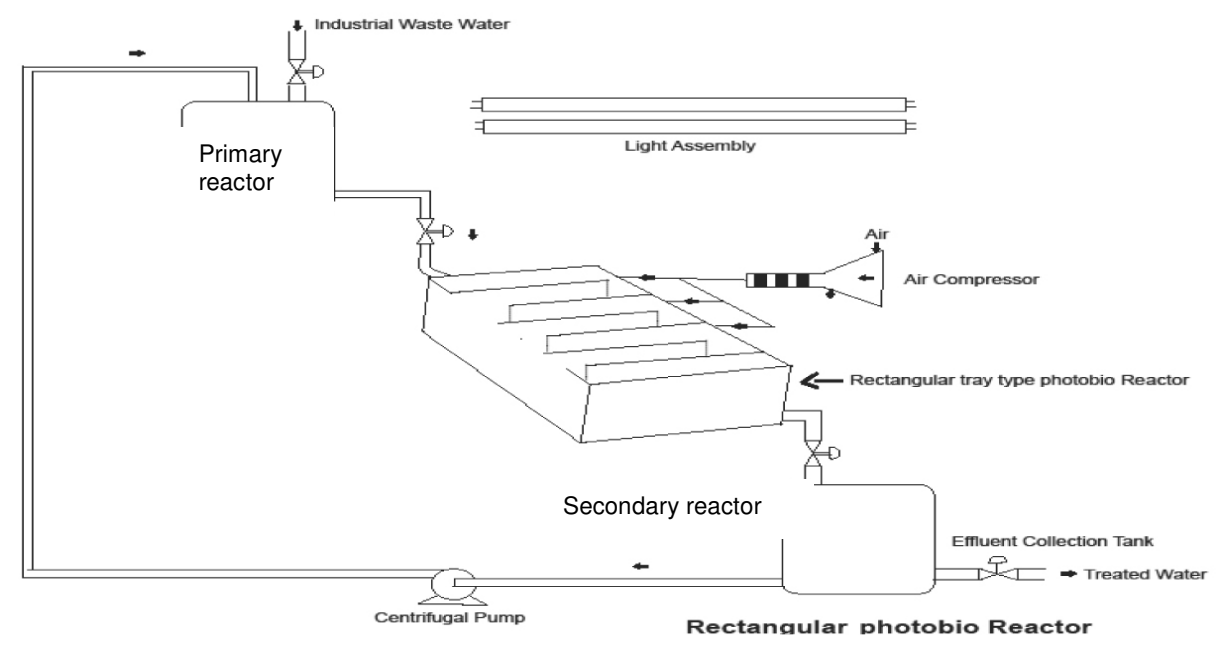

Fig. 1 The schematic of experimental setup of two stage photobioreactor .

A Poly urethane foam having thickness of $1 \mathrm{~mm}$ were fixed on the base of the continuous reactor to immobilize the cyanobacterial filaments. Out let of the primary reactor was connected to the inlet of the secondary reactor. The secondary reactor was mounted inclined $\left(10-15^{0}\right)$ in position in order to achieve a gravity flow inside the reactor . Both the reactors were inoculated with the acclimatied stains of microalagae for the developmentof the biofilm. Three different concentrations of dairy waste water were used for the present study. Out let valve of the primary reactor was closed and low strength effluent (LSE) was added to the primary reactor. Out let of the primary reacor was opened after $24 \mathrm{~h}$ of treatment in the primary reactor. The waste water was then allowed to flow into secondary reactor at a flow rate of $10 \mathrm{ml} \mathrm{min}{ }^{-1}$. Waste water samples were collected fom the outlet of the reactor for analysis. Medium strength Effluent (MSE) and High Strength Effluent(HSE) were also treated as per the above procedure. The biomass developed was harvested by filtering the water samples through nylon mesh.

\subsection{Water Quality Analysis}

Approximately $100 \mathrm{~mL}$ microalgae suspension was taken out from each photobioreactor at every $6 \mathrm{~h}$ intervals and filtered through absorbant cotton and analyzed for phosphate, total hardness ammoniacal nitrogen, total, BOD and COD [11]. The removal percentage (RP) and removal rate $(\mathrm{RR})$ were calculated by the following formulas: $\mathrm{RP}(\%)=\left(\mathrm{C} 0 \_\mathrm{Ct}\right) / \mathrm{C} 0, \mathrm{RR}\left(\mathrm{mg} \mathrm{L}_{-} 1\right.$ day_1 $)=\left(\mathrm{C} 0 \_\mathrm{Ct}\right) /\left(\mathrm{t} \_\mathrm{t} 0\right)$, where $\mathrm{Ct}$ and $\mathrm{C} 0$ are the nutrients concentration at time $\mathrm{t}$ and the beginning, respectively.

\subsection{Estimation of Lipids and Fatty Acid}

Biomass developed within the reactor was efficiently harvested for the analysis of lipids and fatty acids. $50 \mathrm{mg}$ of wet biomass was taken from the harvested biofilm and ground well with chloroform methanol. The lipid content was estimated by the sulpho- phospho vanillin method [12] A known volume of extract was saponified and fatty acid methyl ester were produced followed by extraction of fatty acids in 1:1 mixture of hexane and anhydrous diethyl ether [13]. The organic extract was analyzed using Gas Chromatography. The individual fatty acids were identified and quantified by using the FAME standards under similar conditions. The results were expressed in $\mathrm{mg} \%$ of lipid. 


\section{RESUlt AND DisCUSSION}

\subsection{Biomass Production and Specific Growth Rate}

The micro algae brought from the Effluent Treatment Plant (ETP) of Milma Dairy, Kochi were dominated by Oscillatoria sp .of blue green algae. It strongly reveals its high tolerance to the effluent. Blue green algae have high nutrient removal capacity and they are likely to tolerate the highly variable conditions that characterize polluted effluents [14]. The specific growth rate of the species in BG 11 medium showed $0.05 \mathrm{~d}^{-1}$ whereas the organism showed $0.49,0.52$ and $0.47 \mathrm{~d}^{-1}$ in LSE, MSE and HSE respectively. Spirulina platensis has specific growth rate between 0.46 and $0.58 \mathrm{~d}^{-1}$ whereas that of Spirulina maxima is between 0.26 and $0.45 \mathrm{~d}^{-1}$ at 30 $35^{0} \mathrm{C}[15]$

\subsection{Biofilm Development and Acclimatization}

The blue green algal filaments could grow well inside the primary reactor and biofilm was developed over the woven coir mat. The filaments get acclimatized with the polyurethane foam fixed inside the secondary reactor

\subsection{Chemical Characteristics of Synthetic Dairy Effluent}

Chemical characteristics of the three different concentrations of synthetic effluent are given in the table 1.

Table 1 Chemical characteristics of synthetic Dairy effluent

\begin{tabular}{lccc}
\hline Parameters & $\begin{array}{c}\text { low strength } \\
\text { (LSE) }\end{array}$ & $\begin{array}{c}\text { medium strength } \\
\text { (MSE) }\end{array}$ & $\begin{array}{c}\text { high strength } \\
\text { (HSE) }\end{array}$ \\
\hline $\mathrm{pH}$ & 7.2 & 7.9 & 8.5 \\
Phosphate $\left(\mathrm{mg} \mathrm{L}^{-1}\right)$ & 7.4 & 12 & 18 \\
Ammo.Nitrogen $\left(\mathrm{mg} \mathrm{L}^{-1}\right)$ & 21.5 & 64 & 83 \\
Hardness $\left(\mathrm{mg} \mathrm{L}^{-1}\right)$ & 40 & 60 & 82 \\
$\mathrm{BOD}\left(\mathrm{mg} \mathrm{L}^{-1}\right)$ & 300 & 950 & 1500 \\
$\mathrm{COD}\left(\mathrm{mg} \mathrm{L}^{-1}\right)$ & 950 & 1500 & 2500 \\
\hline
\end{tabular}

\subsection{Nutrient Removal in the Primary and Secondary Photobioreactor}

\subsection{Reduction of Phosphate, Total Hardness and Ammoniacal Nitrogen}

Nutrient concentrations in all of the three different waste waters decreased during the culturing time. Phosphate content of the LSE was reduced to 4.5 from an initial amount of $7.4 \mathrm{mgL}^{-1}$ (fig 2). 
Civil Engineering and Urban Planning: An International Journal (CiVEJ) Vol.3, No.2, June 2016

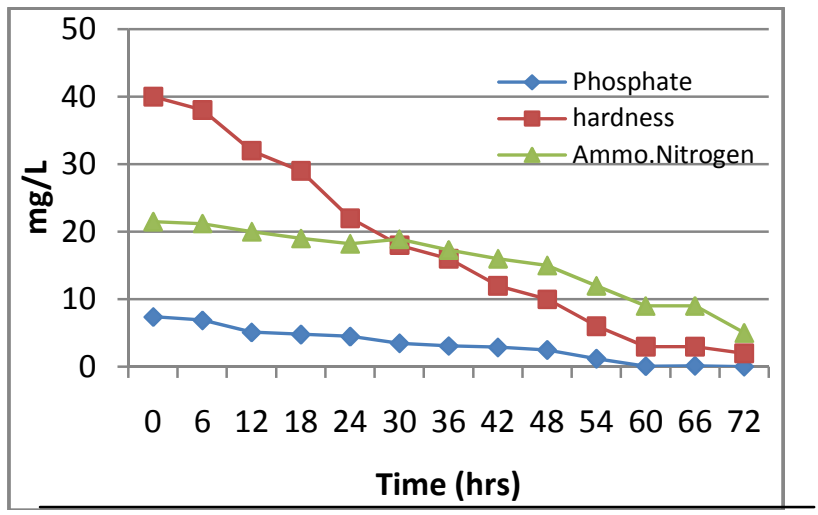

Fig 2. Removal of phosphate, hardness, ammoniacal nitrogen from LSE

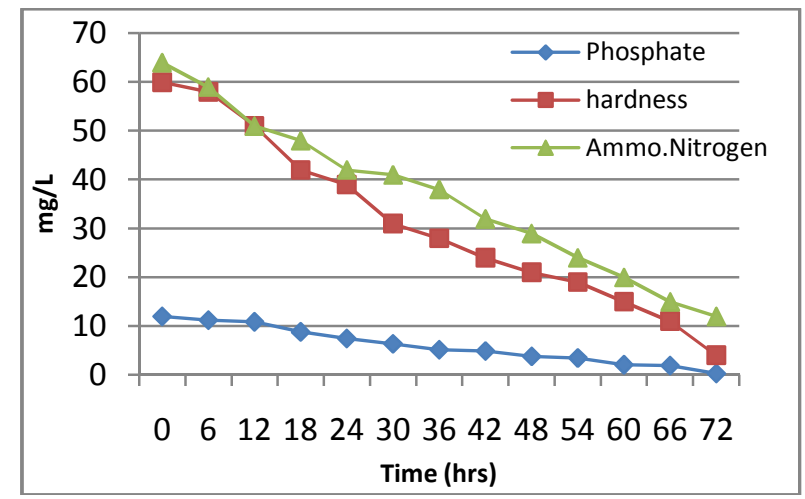

Fig 3. Removal of phosphate, hardness, ammoniacal nitrogen from MSE

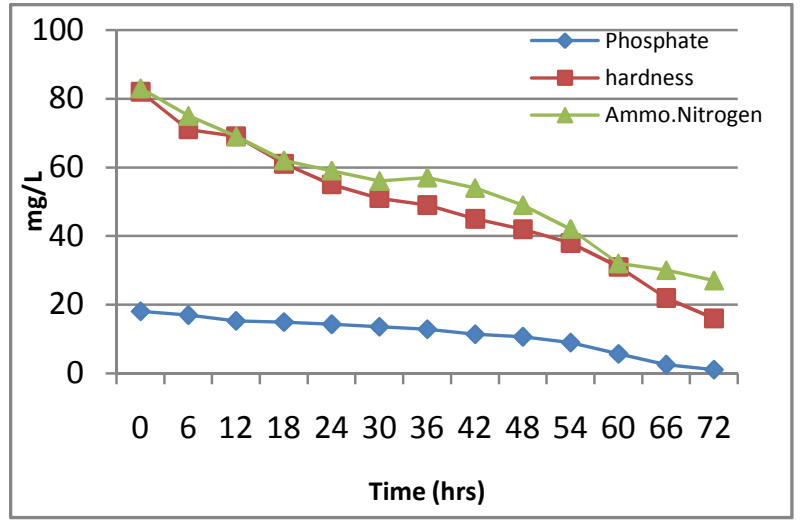

Fig 4: Removal of phosphate, hardness, ammoniacal nitrogen from HSE

Phosphorous removal is important as it is a limiting nutrient for algae growth in many fresh water systems[16]. By the growth of blue green algal filaments in the primary reactor, $45 \%$ of the hardness was removed from LSE. BOD of the LSE was reduced to 120 from an initial amount $300 \mathrm{mgL}^{-1}$ after treatment in the primary photobioreactor. Ammoniacal nitrogen was found to be a dangerous problem faced by almost all food processing industries like dairy 
industries[17]. The organism could tolerate well in the MSE by reducing the phosphate content to 7.5 from an initial amount of $12 \mathrm{mgL}^{-1}$. The total hardness of the MSE was also reduced after $24 \mathrm{~h}$ of treatment (fig 3). Removal percentage of ammoniacal nitrogen was found to be increased to $34.4 \mathrm{mgL}^{-1}$ in MSE compared to LSE. This may be due the growth of Oscillatoria sp. in the photobioreactor. Removal rate of phosphate was decreased with the increase in the concentration of waste water, but hardness of HSE was reduced to 55 from $82 \mathrm{mgL}^{-1}$ after $24 \mathrm{~h}$ of treatment (fig 4). Secondary phtobioreactor performed well in the removal of phosphate from LSE. Reduction of $94-99.5 \%$ in phosphate was observed after $48 \mathrm{~h}$ of treatment from the three different concentrations of synthetic waste water. Growth of blue green algae in waste water containing phosphate bring about solubilization of insoluble phosphate. Total hardness of MSE was reduced to 4 from $39 \mathrm{mgL}^{-1}$ at the outlet of the secondary photobioreactor. cultivation of Cyanobacterium in the dairy effluent lead to utilization of free $\mathrm{CO} 2$ and also it absorbed significant amounts of both Ca++_as well as $\mathrm{Mg}++$ [ 18]. Removal of $81 \%$ of the ammoniacal nitrogen was observed from the MSE, but removal rate was decreased with the increase in the concentration of ammoniacal nitrogen. However, it was reduced to $27 \mathrm{mgL}^{-1}$ from $59 \mathrm{mgL}^{-1}$ after $48 \mathrm{~h}$ of treatment in the continuous photobioreactor. The physical and chemical parameters of wastewater quality such as nitrate, phosphate, hardness, etc., were greatly reduced by the growth of Chlorella pyrenoidosa on dairy waste water [19].

\subsubsection{Reduction of BOD and COD}

It is evident to see that there is a continuous reduction of BOD in this experimental set up. BOD of HSE was reduced to $50 \mathrm{mg} \mathrm{L}^{-1}$ from an initial amount of $1500 \mathrm{mg} \mathrm{L}^{-1}$ after $72 \mathrm{~h}$ of treatment in both the reactors (fig 5)..

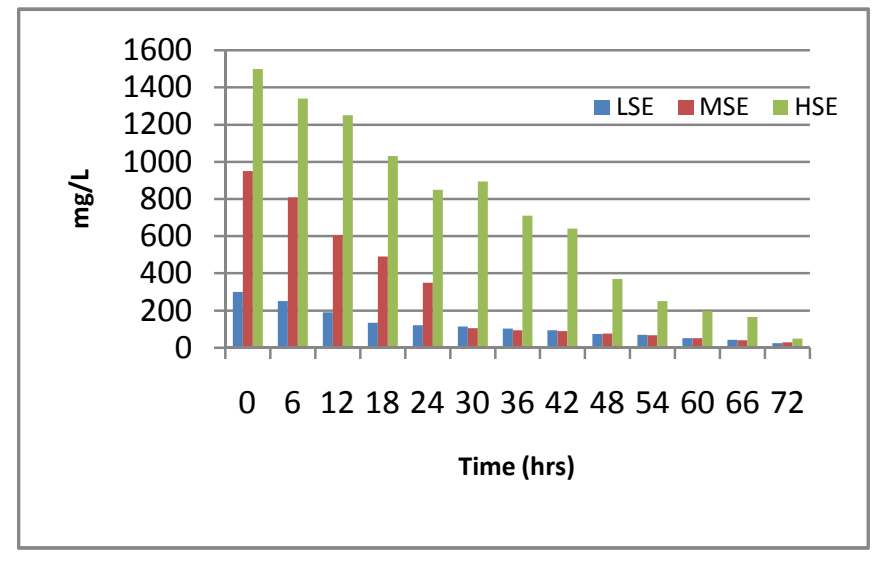

Fig 5. Removal of BOD from low, medium, and high strength effluent 


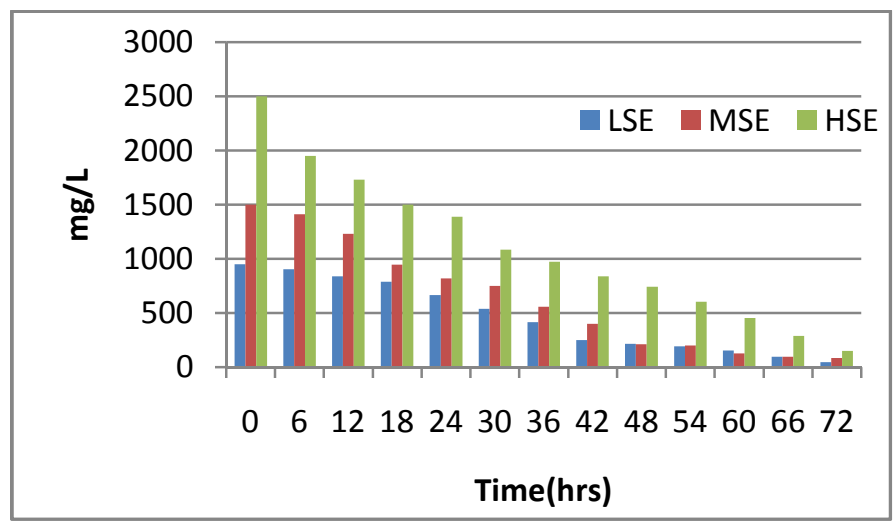

Fig 6. Removal of COD from low,medium, and high strength effluent

COD was reduced to $85 \mathrm{mg} \mathrm{L}^{-1}$ from an initial value of $1500 \mathrm{mg} \mathrm{L}^{-1}$ from MSE . Removal of $94 \%$ COD was achieved after treatment in the two stage photobioreactors (fig 6). Percentage of reduction BOD and COD obtained in case of low, medium and high strength effluent were $91 \%, 96 \%$ and $97 \%$ and $95 \%, 94 \%$ and $94 \%$ respectively. It may be due to the uptake of nutrients from the waste water. More over that algae play a major role in supplying oxygen to the bacterial population for the breakdown of complex organic matter and few species of microalgae can use dissolved organic carbon as carbon sources [20]. The system could perform well for the removal of phosphate, BOD and COD even in the high strength effluent concentrations. The discharge of ammonia from dairy shed effluent can cause significant adverse effects. The system could not perform well for the removal of ammonia cal nitrogen from the high strength waste water, but incorporation of other algal strains may reduce the problem. Oscillatoria sp.could grow well in the system especially in the secondary photobio reactor. Raw wastewater as well as treated effluent most contains significant amounts of bioavailable inorganic substances such as $\mathrm{NH} 4+$, NO3-.. There are a large number of studies on the treatment of industrial, municipal andagricultural waste waters by micro algal culture systems [21],. Micro algae can grow in effluents and produce valuable biomass while they remove organic contentand minerals for building the biomass

\subsection{Lipid and Fattyacid Profile}

The organism showed 40-45 mg \% lipid in the stationary phase.Composition of lipid varies with the environmental conditions Fatty acid composition of the harvested biomass from the reactor after treatment is given in the Table 2.

Fatty Acid Methyl Esters are the principle components of biodiesel. Biodiesel which can be produced from these crude lipids will have a high cetane number and a high oxidative stability. Algal oil is considered as one of the most potent resources for biofuels and is limited mainly by the yield under phototrophic cultivation. Recently Chlorococcum sp were cultivated in Dairy effluent for biofuel production [22]. Lipid content and fatty acid profile are key factors to consider when selecting algae for fuel production. GC analysis of FAMEs from the algal oil showed that saturated fatty acid content was high in the oil. Major fatty acid from Oscillatoria sp.include palmitic acid $(23.12 \%)$ followed by oleic acid $(10.16 \%)$ stearic acid $(8.58 \%)$. Linoleic acid (4.6 $\%)$ and myristo oleic acid (15.47\%). 
Civil Engineering and Urban Planning: An International Journal (CiVEJ) Vol.3, No.2, June 2016

Table 2. Fatty acid profile of Oscillatoria sp. grown in Dairy effluent

\begin{tabular}{|c|c|}
\hline Fatty acids & mg(\%) of lipid \\
\hline CAPRYLIC ACID(C 10:0) & 3.24 \\
\hline LAURIC ACID( C 12: 0) & 2.05 \\
\hline TRIDECANOIC ACID(C13:0) & 2.5 \\
\hline MYRISTOLEIC ACID(C 14:0) & 15.47 \\
\hline PENTADECANOIC ACID(C15:0) & 4.03 \\
\hline PALMITIC ACID (C 16:0) & 23.12 \\
\hline PALMITOLEIC ACID(C $16: 1)$ & 21.05 \\
\hline HEPTADECENOIC ACID(C17:0) & 2.16 \\
\hline STEARIC ACID(C $18: 0)$ & 8.58 \\
\hline OLEIC ACID(C $18: 1 \mathrm{~N} 9 \mathrm{c})$ & 10.16 \\
\hline LINOLEIC ACID(C $18: 2)$ & 4.6 \\
\hline
\end{tabular}

Fatty acids indicated for good biodiesel properties include C14:0, C16:0, C16:1, C18:0, C18:1 and C18:2 etc. [23]These results strongly reveals that the harvested biomass from the secondary reactor can be used for the biofuel production. The production of alternative sources of fuel such as the oil from microalgae has been shown to be effective at the laboratory and pilot scale [24].

\section{CONClusion}

Photo bioreactors can play a dual role while using industrial waste water as nutrient source for producing biomass. The present investigation supported that Oscillatoria sp can be cultured in dairy effluent as a nutrient source for biodiesel production. The organism showed relatively high growth rates in waste water compared to the standard growth medium. Initially the heavy nutrient load of the waste water was reduced by the treatment in the primary reactor where the acclimatized blue green algal filaments as well as the filer bed performed in a better way. The level of phosphate, hardness and ammoniacal nitrogen in the medium strength effluent (MSE) were reduced by $97 \%, 93 \%, 81 \%$ respectively. BOD and COD of the three different concentrations of waste water could be effectively removed by the treatment system. Continuous PBR with Oscillatoria sp. is no doubt, a novel efficient appliance which can be adopted for treatment of waste water containing high BOD and COD. Presence of palmitic (16:0), oleic (18:1), stearic (18:0), linoleic (18:2) and linolenic (18:3) acids strongly supports that the cultivated algae from the reactor can be used for the biofuel production. A careful considerations of various design parameters of PBR with immobilized strains promises greater efficiency in the cultivation of micro algae for biodiesel production. Outdoor studies with pilot scale photo bioreactors should be carried out in further study.

\section{ACKNOWLEDGEMENT}

We would like to acknowledge financial help from University Grants Commission, Govt. of India in the form of Post Doctoral Fellowship for this work. We thank Milma Dairy, Tripunithura, Kochi for providing us biofilm from Effluent Treatment Plant. 
Civil Engineering and Urban Planning: An International Journal (CiVEJ) Vol.3, No.2, June 2016

\section{References}

[1] Samori, G., Samori, C., Guerrini, F., Pistocchi, R., (2013). Growth and nitrogen removal capacity of Desmodesmus communis and of a natural microalgae consortium in a batch culture system in view of urban wastewater treatment: part I. Water Res. 47, 791-801.

[2] Zhu, L., Wang, Z., Shu, Q., Takala, J., Hiltunen, E., Feng, P., Yuan, Z., (2013). Nutrient removal and biodiesel production by integration of freshwater algae cultivation with piggery wastewater treatment. Water Res. 47, 4294-4302.

[3] Van den Hende, S., Carre, E., Cocaud, E., Beelen, V., Boon, N., Vervaeren, H., (2014) Treatment of industrial wastewaters by microalgal bacterial flocs in sequencingbatch reactors. Bioresour. Technol. $161,245-254$.

[4] Ramos Tercero, E.A., Sforza, E., Morandini, M., Bertucco, A., (2014). Cultivation of Chlorella protothecoides with urban wastewater in continuous photobioreactor: biomass productivity and nutrient removal. Appl. Biochem. Biotechnol. 172, 1470-1485.

[5] Farooq, W., Lee, Y.C., Ryu, B.G., Kim, B.H., Kim, H.S., Choi, Y.E., Yang, J.W., (2013). Twostagecultivation of two Chlorella sp. strains by simultaneous treatment of brewery wastewater and maximizing lipid productivity. Bioresour. Technol.132, 230-238

[6] Lu. W, Wang, Wang X, Yuan Z.,(2015). Cultivation of Chlorella sp. using raw dairy wastewater for nutrient removal and biodiesel production: Characteristics comparison of indoor bench-scale and outdoor pilot-scale cultures. Bioresour. Technol 192, 382-388.

[7] Rawat I, Ranjith Kumar R, Mutanda T, Bux F. (2013) Biodiesel from microalgae: a critical evaluation from laboratory to large scale production. Appl Energy; 103:444-67

[8] Cai Ting, Y. Park Stephen , Racharaks Ratanachat, Li Yebo ,( (2013), Cultivation of Nannochloropsis salina using anaerobic digestion effluent as a nutrient source for biofuel production, Applied Energy 108 486-492

[9] Daft, M.J.,(1995) Cyanobacteria: Isolation, Interaction \& Ecology. Methods in aquatic bacteriology . University of Dunndee,DD 14HN, Scotland.

[10] Desikachary, T.V.1(959). Cyanophyta. Pub.by Indian Council of Agricultural Research. New Delhi

[11] American Public Health Association (APHA)., (1998). Standard Methods for the Examination of Water and Waste water. American Public Health Association. Washington D.C.

[12] Barnes, $\mathrm{H}$ and Blackstock, J (1973) ,Estimation of lipids in marine animals,tissues: Detailed investigation of the sulpho-phospho vanillin method for total lipids. J.Exp.Mar.Biol.Ecol.,12 (1):103-118.

[13] Miller, L.and Berger (1985). Bacteria identification by Gas Chromatography.Application Note.228241, Hewlett Packard.

[14] Subramanian, G. and Uma, L. (1996). Cyanobacteria in pollution control. J. of Scientific and Indutrial Research. 55: 685-692.

[15] Oliveira,M.A.C.L.,Monteiro, M.P.C.,Robbs,P.G. and Leite, S.G.F (1999), Growth and Chemical composition of Spirulina maxima and Spirulina platensis biomass at different temperatures. Aquaculture International .7:261-275.

[16] Sara, R.A., Nima, M.N., Saeedeh, S., Azam, S., Aboozar, K., Pegah, M., Mohammad, A.M., Younes, G., (2014). Removal of nitrogen and phosphorus from wastewater using microalgae free cells in batch culture system. Biocatal. Agric. Biotechnol. 3, 126-131.

[17] Lu Weidong, Wang Zhongming, Wang Xuewei, Yuan Zhenhong (2015) Cultivation of Chlorella sp. using raw dairy wastewater for nutrient removal and biodiesel production: Characteristics comparison of indoor bench-scale and outdoor pilot-scale cultures, Bioresource Technology 192 382-388

[18] Sharma, Kanika., Pooja, Sethia. and Ashish, Maheswari., (2004). Biological treatment of Dairy Effluent by Cyanobacteria In: Microbial Biotechnology. (ed.) Trivedi, P.C.pp.345-386. 
Civil Engineering and Urban Planning: An International Journal (CiVEJ) Vol.3, No.2, June 2016

[19] Kothari, R., Pathak, V.V., Kumar, V., Kumar, V., Singh, D.P., (2012). Experimental study for growth potential of unicellular alga Chlorella pyrenoidosa on dairy wastewater: an integrated approach for treatment and biofuel production. Bioresour. Technol. 116, 466-470.

[20] Kothari, R., Prasad, R., Kumar, V., Singh, D.P.,( 2013). Production of biodiesel from micro algae Chlamydomonas polypyrenoideum grown on dairy industrialeffluent. Bioresour. Technol. 144, 499503.

[21] Van den Hende, S., Carre, E., Cocaud, E., Beelen, V., Boon, N., Vervaeren, H., (2014).Treatment of industrial wastewaters by microalgal bacterial flocs in sequencing batch reactors. Bioresour. Technol. 161, 245-254.

[22] Sabeela Beevi Ummalyma, Sukumaran Rajeev K. (2014) Cultivation of microalgae in dairy effluent for oil production and removal of organic pollution load, Bioresour. Technol. 165 295-301

[23] Schenk, P.M., Thomas-Hall, S.R., Stephens, E., Marx, U.C., Mussgnug, J.H., Posten, C.,Kruse, O., Hankamer, B., (2008). Second generation biofuels: high-efficiency microalgae for biodiesel production. Bioenergy Res. 1, 20-43.

[24] Fon Sing, S., Isdepsky, A., Borowitzka, M., Lewis, D., (2014). Pilot-scale continuous recycling of growth medium for the mass culture of a halotolerant Tetraselmis sp. in raceway ponds under increasing salinity: a novel protocol for commercial microalgal biomass production. Bioresour. Technol. 161, 47-54. 